\title{
Research Paper \\ Resistin Changes Following Aerobic Exercise and its Relationship With Fertility in Male Rats With Type 2 Diabetes
}

\author{
Abbas Saremi ${ }^{1}$ (D), Mohammad Parastesh $^{1}$ (1), Leili Mohammadi ${ }^{1}$
}

Key words:

Resistin, Aerobic exercises, Reproductive health, Rats

\section{A B STRACT}

Aims Resistin is secreted by adipose tissue and could be the link between diabetes and infertility. This study aimed to investigate the alteration of resistin following aerobic exercise training in diabetic rats and its possible interaction with sperm parameters.

Methods \& Materials In this experimental study, 30 male Wistar rats (age: 56 days, weight: 200-250g) were randomly divided equally into three groups of healthy control, diabetic control, and diabetic aerobic exercises. Diabetes was induced with a unique intraperitoneal injection (65 mg/kg body weight) of streptozotocin. Seven days after the injection and after 12 hours of fasting, the animals with blood glucose levels of $\geq 250 \mathrm{mg} / \mathrm{dL}$ were considered diabetic. Seven days after the induction of diabetes, the animals in the exercise group were subjected to progressive aerobic training (treadmill running for $1 \mathrm{~h}, 27 \mathrm{~m} / \mathrm{min}$, $5 \mathrm{~d} / \mathrm{wk})$. After 10 weeks of exercise, the sperm quality and resistin concentrations were measured. The obtained data were compared using Analysis of Variance (ANOVA) $(P<0.05)$.

Findings The induction of diabetes significantly decreased sperm count $(P=0.001)$, motility $(P=0.001)$, viability $(P=0.001)$, and morphology $(P=0.01)$. The sperm parameters, such as count $(P=0.03)$ and viability $(P=0.002)$ were significantly higher in the diabetic exercise group, compared to the diabetic sedentary group. No significant changes were found in resistin levels between diabetic exercise and diabetic sedentary groups $(\mathrm{P}=0.40)$.

Conclusion The collected results indicated that the 10-week aerobic training regimen improved sperm quality, independent of changes in resistin levels, in type 2 diabetes mellitus rat models.

\section{Extended Abstract}

\section{Introduction}

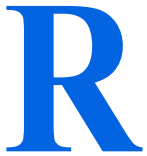

esistin is secreted from adipose tissue and could be a link between diabetes and infertility. Evidence suggests that resistin negatively impacts the hypo- thalamic-pituitary-gonadal axis; accordingly, affecting male and female fertility.

Nogueiras et al. found that resistin is a new endocrine that binds between energy homeostasis and reproduction; increasing the expression of the resistin gene by the testis reduces the function of leydig cells. Ultimately, it reduces testosterone production [1]. In addition, Normandin et al. observed in diabetic men that high levels of serum

\section{* Corresponding Author:}

\section{Mohammad Parastesh, PhD.}

Address: Department of Exercise Physiology, Faculty of Sport Sciences, Arak University, Arak, Iran.

Tel: +98 (916) 3622668

E-mail: m-parastesh@araku.ac.ir 
resistin were associated with hypogonadism in the testes and infertility [2]. Christos et al. documented that resistin negatively affected the hypothalamic-pituitary-gonadal axis; consequently, affecting male and female fertility [3]. The current study aimed to investigate the changes in resistin following aerobic exercise in diabetic mice and its relationship with sperm parameters.

\section{Materials and Methods}

The present experimental study was performed in a laboratory. The study sample included 30 Wistar breed rats that were randomly obtained from Arak University in 2015.

Glucose concentration was measured by enzymatic-colorimetric method (Pars Azmoun Company, Iran). Insulin was evaluated by radioimmunoassay (Monobind Inc, USA). Measuring resistin serum levels with sensitivity of $0.16 \mathrm{pg} /$ $\mathrm{mL}$ and the range of $0.60-60 \mathrm{pg} / \mathrm{mL}$ was performed by Rat ELISA Kit, Eastbiopharm (made in China; Under the USA license). These assessments were conducted according to the manufacturer's instructions. Insulin resistance was then calculated using the Homeostasis Model Assessment (HOMAIR) as an insulin resistance index. The following Formula 1 was implemented for this purpose:

\section{HOMA-IR $=$ insulin $(\mu \mathrm{u} / \mathrm{ml}) \times \operatorname{glucose}(\mathrm{mmol} / \mathrm{L}) 22.5$}

\section{Results}

The induction of diabetes significantly reduced the number $(\mathrm{P}=0.001)$, mobility $(\mathrm{P}=0.001)$, survival $(\mathrm{P}=0.001)$, and morphology $(\mathrm{P}=0.01)$ of sperm. Sperm indicators, such as the number $(\mathrm{P}=0.03)$ and survival $(\mathrm{P}=0.002)$ were significantly higher in the exercise diabetes group, compared to the sedentary one. There was no significant difference in resistin levels between exercise and sedentary study groups $(\mathrm{P}=0.40)$ (Table 1).

\section{Discussion}

Palmer et al. reported that 10 weeks of diet and exercise reduced adipose tissue and improved sperm number, motility, and morphology in obese mice [4]. In addition, Hakonsen et al. argued that obesity is associated with decreased semen quality and altered sex hormone profile. Moreover, participation in a 14-week weight-loss program improved semen quality and fertility [5]. Furthermore, Parastesh et al. documented that aerobic exercise increased testosterone and sperm production, as well as fertility in healthy individuals [6]. In line with the above-mentioned results, in the present study, after aerobic exercise, sperm factors, such as sperm count and viability improved in the investigated mice. Plessis et al. also reported that moderateintensity exercise may increase male fertility. This could be achieved through mechanisms, such as improving glycemic status, endocrine status, oxidative stress, and body composition [7].

Based on the present study data, the improvement of sperm status in diabetic mice was not related to serum resistin changes. Accordingly, other mechanisms might be involved that require further exploration. Improvement in sperm parameters (sperm count, motility, viability, \& morphology) appears to be associated with insulin resistance after 10 weeks of aerobic exercise by decreasing blood glucose level.

The study limitation included investigating diabetes specimen; diabetes caused by streptozotocin-nicotinamide is an imitation of the type 1 diabetes induction model. Thus, this model is not exactly a simulation of type 2 diabetes in humans. The pathophysiological and molecular aspects of type 1 diabetes and type 2 diabetes are common; however, some characteristics may be different and generally limit this pattern to type 2 diabetes and insulin resistance.

Table 1. Comparing sperm parameters in different study groups

\begin{tabular}{ccccc}
\hline \multirow{2}{*}{ Variable } & \multicolumn{3}{c}{ Mean \pm SD } & P* \\
\cline { 2 - 4 } & Healthy Control Group & Diabetic Control Group & Diabetic Aerobic Exercise & \multirow{2}{*}{0.001} \\
\hline Sperm count (106) & $39.3 \pm 13.5$ & $11.75 \pm 5.7$ & $26.3 \pm 13.2$ & 0.001 \\
\hline Mobility (\%) & $60.8 \pm 6.5$ & $32.5 \pm 1.1$ & $40.3 \pm 6.5$ & 0.001 \\
\hline Survival (\%) & $77.5 \pm 4.6$ & $29.78 \pm 16.2$ & $41.7 \pm 7.2$ & 0.01 \\
\hline Morphology (\%) & $95.4 \pm 1.3$ & $85.25 \pm 7.5$ & $88.5 \pm 8.8$ & Quarterly of \\
\hline
\end{tabular}




\section{Conclusion}

The obtained data suggested that a 10 -week aerobic exercise program improved sperm quality in rats with type 2 diabetes, i.e. independent of resistin changes.

\section{Ethical Considerations}

Compliance with ethical guidelines

The code of ethics (IR.Arakmu.rec.1394.329) has been obtained from the Ethics Committee of Research Projects of Arak University of Medical Sciences.

\section{Funding}

This article is taken from the M.Sc. thesis of Lily Mohammadi at Arak University, Faculty of Sports Sciences, Sports Physiology and without receiving financial assistance.

\section{Authors' contributions}

Main idea: Abbas Saremi and Mohammad Parastesh; Writing an article, and final approval of the article: Abbas Saremi, Mohammad Parastesh and Lily Mohammadi; Data collection, and data interpretation: Lily Mohammadi.

Conflicts of interest

The authors declared no conflicts of interest. 


\title{
بررسى تغييرات رزيستين به دنبال تمرينات هوازى و ارتباط آن با بارورى در موشهاى صحرايى نر ديابتى نوع تغيرات
}

\author{
عباس صارمى' هـ، "محمد يرستش' (1) ليلى محمدى'
}

1. ا.كروه فيزيولورى ورزش، دانشكده علوم ورزشى، دانشكاه اراك، اراك، ايران.

\begin{abstract}
حكيد

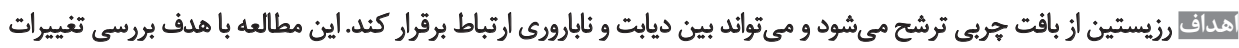

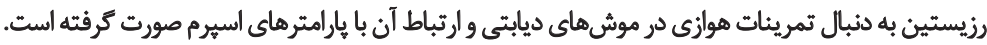

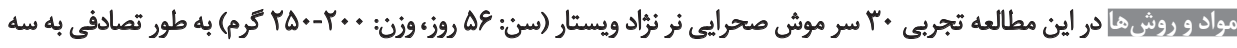

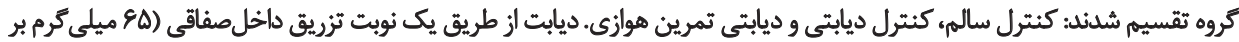

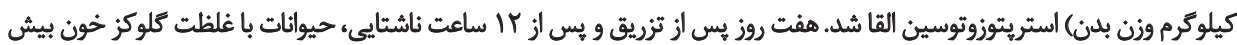

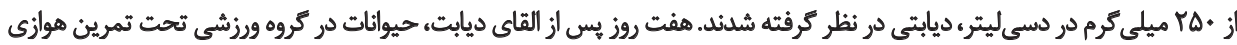

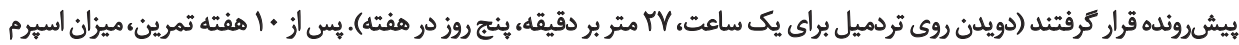

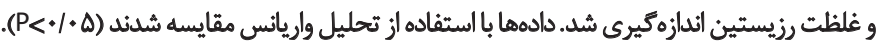

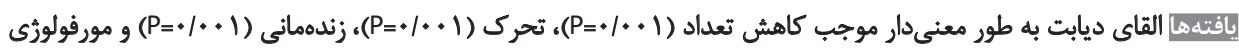

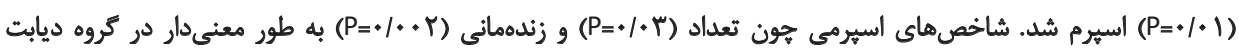

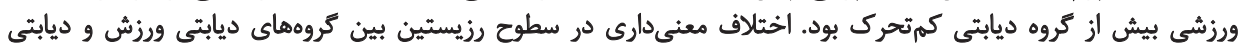

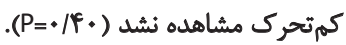

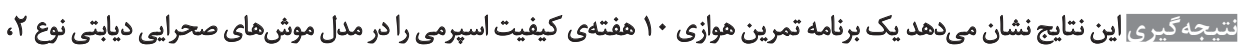

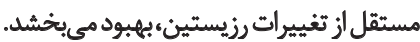

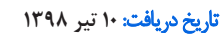

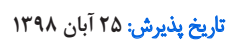
تاريخ اتتشار: با فروردين

هليدوازٔهها:

مقدمه

در مطالعهاى روى موشهاى صحرايى مبتلا به ديابت مليتوس

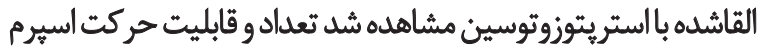

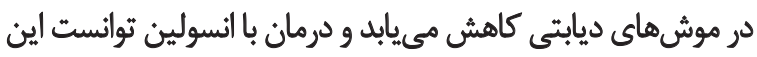

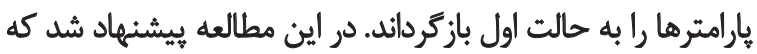

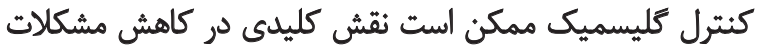

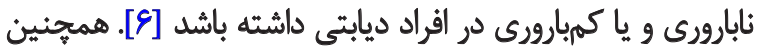

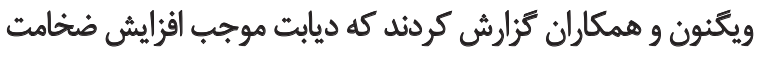

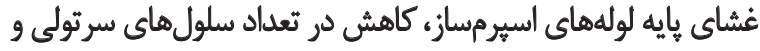

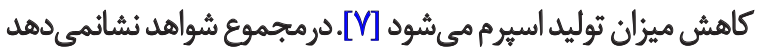

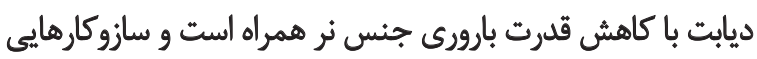

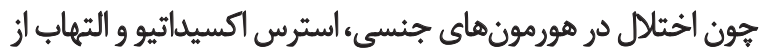
علل احتمالى آن در نظر كرفته شده است [1/].

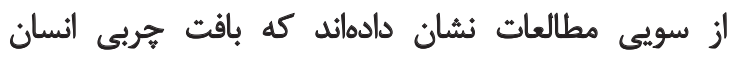

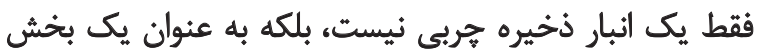

رشد سريع ديابت نوع ب يك مشكل جهاني است كه ناشى از كاهش

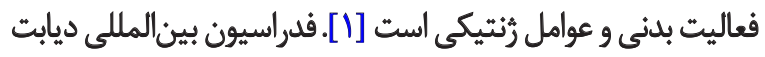

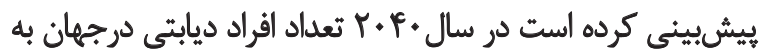

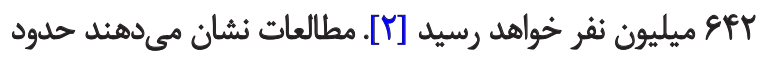

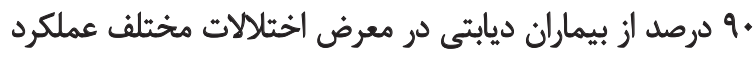

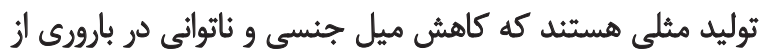

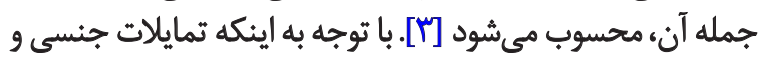

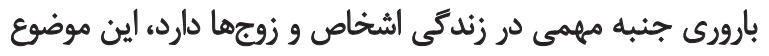

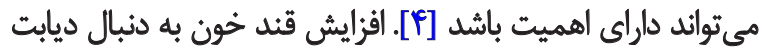

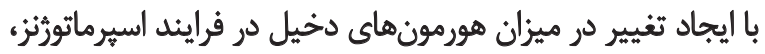

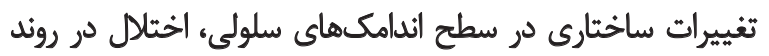

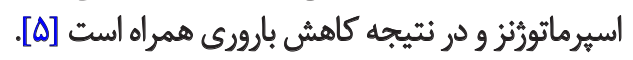


دقيقه از محلول استريتوزوتوسين (ساخت شركت سيخماء آمريكا)

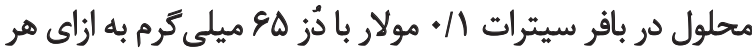

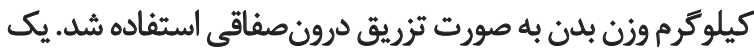

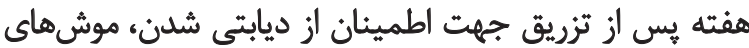

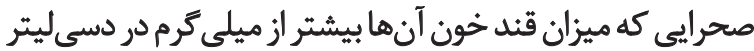

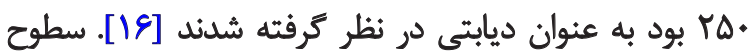

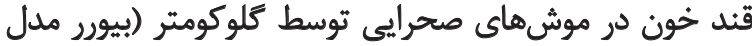

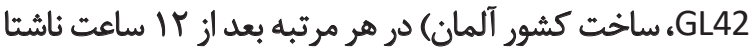

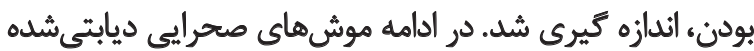

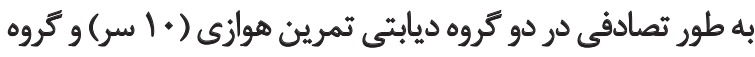

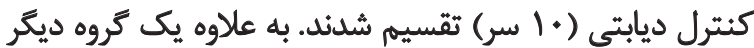

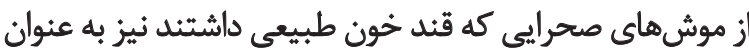
كروه كنترل سالم (• إسر ) در نظر كرفته شدند.

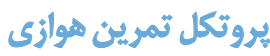

برنامه تمرين هوازى روى تردميل پينجاناله به دليل كنترل

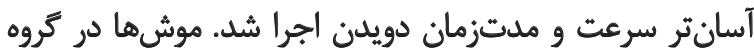

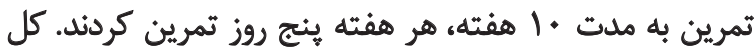

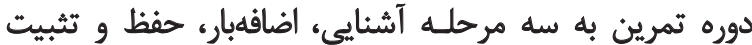

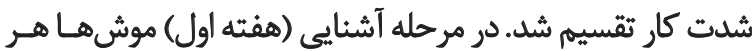

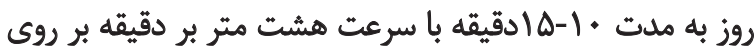

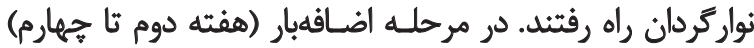

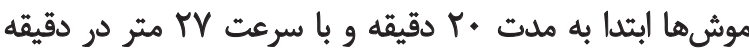

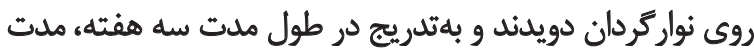

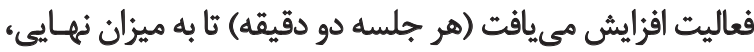

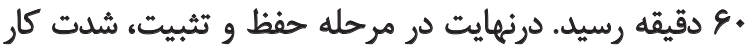

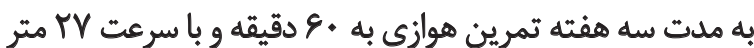

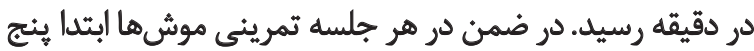

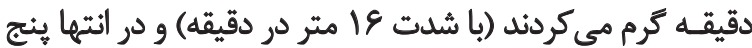

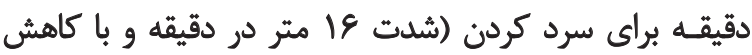

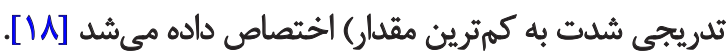

\section{أندازوهيرى هائييوشيميايي}

تمامى موشها، شF ساعت بـ إس از آخرين جلسه تمرين،

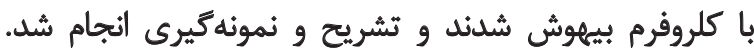

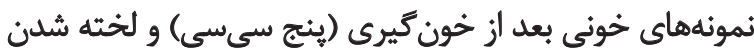

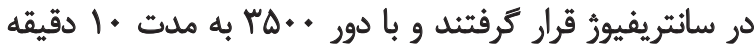

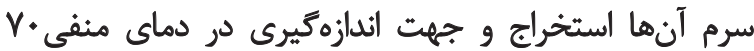

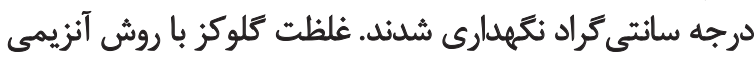

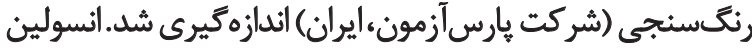
به روش راديوايمنواسى (Monobind Inc, USA) ارزيابى شدئ شيدي

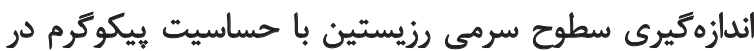

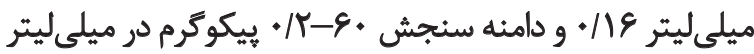

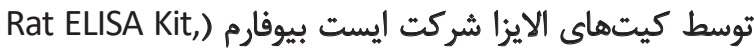

درونريز كه قادر به توليد يروتئينهاى زيستى فعال است كه

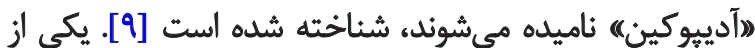

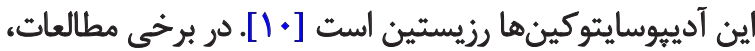

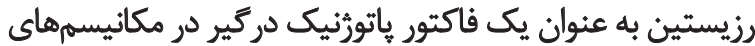

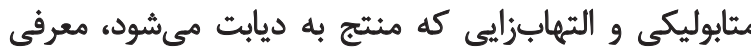

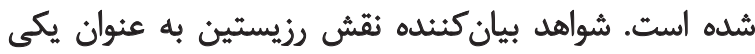

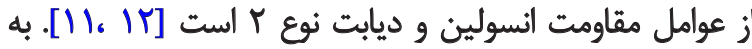

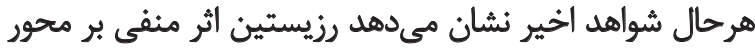

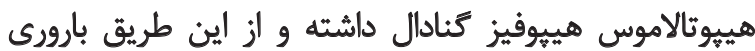

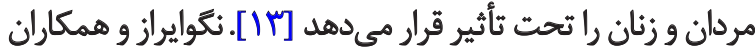

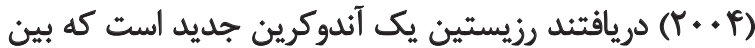

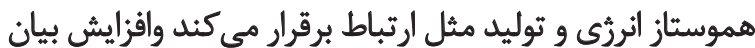

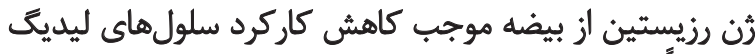

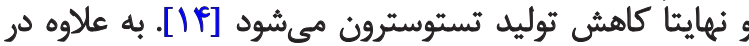

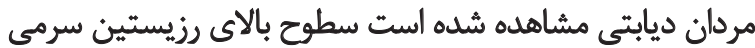

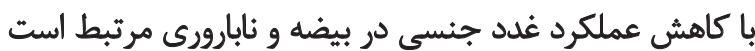

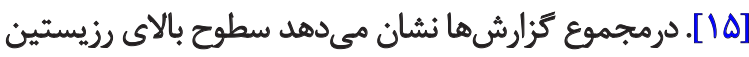
با كاهش اسبرماتوثنز و بارورى در مردان همراه است. از سويى امروزه فعاليت هوازي به عنوان يك راهكار يذيرفتهشده

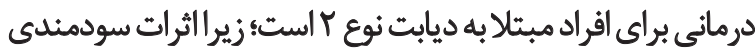

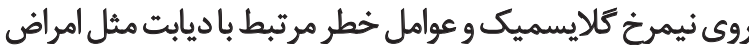

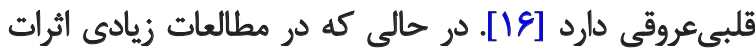

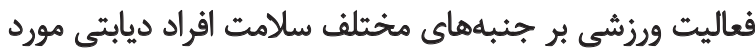

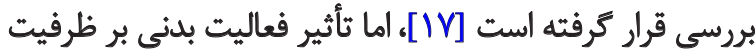

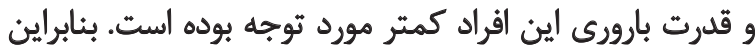

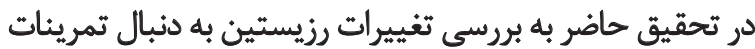

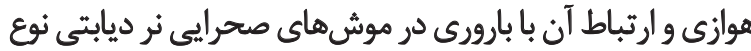

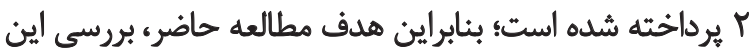

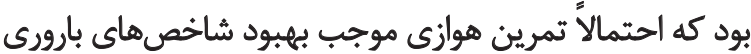

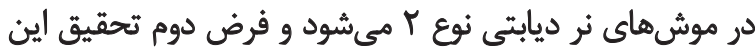

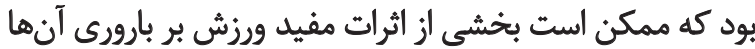
از طريق كاهش رزيستين اعمال شود.

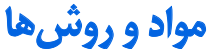

ثيروهش حاضر از نوع تجربى بود كه به شيوه آزمايشكاهى انجام

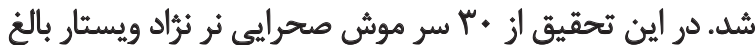

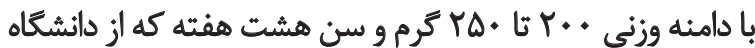

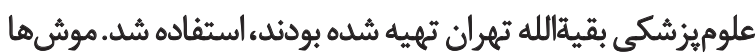

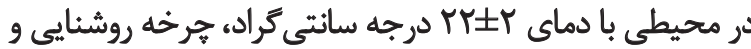

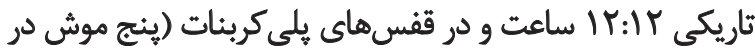

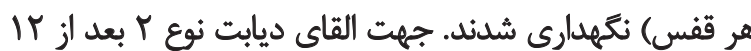

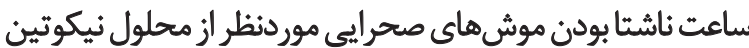

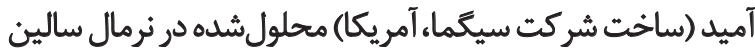

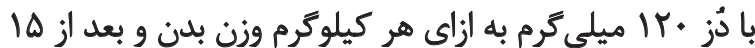


قابليت حيات اسيرم: به منظور بررسى قابليت حيات، اسيرمهاى هر كروه بر اساس دستورالعمل سازمان بهداشت جهانيتي

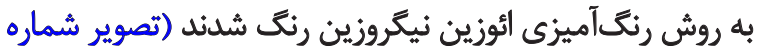

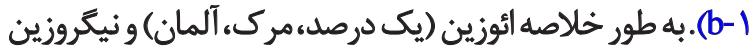

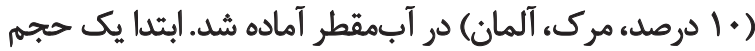

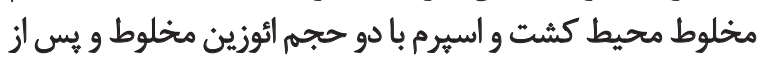

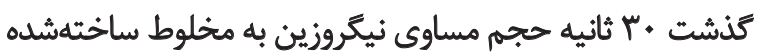

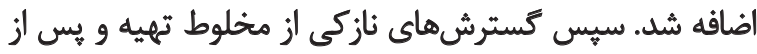

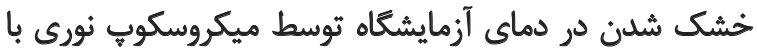

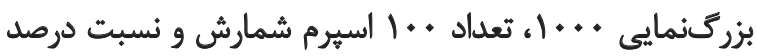

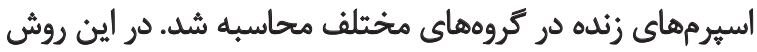

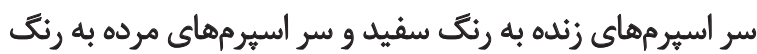

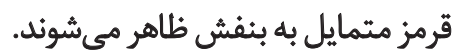

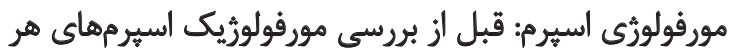

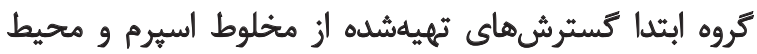

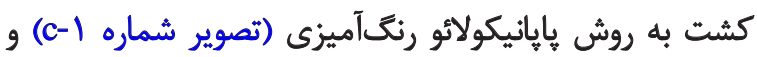

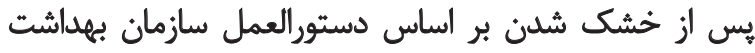

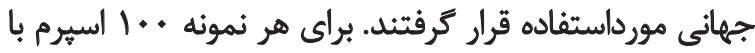

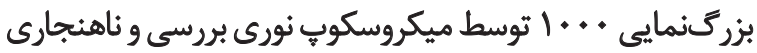

موجود به صورت درصد بيان شد [19] توسط ميكروب نوري

$$
\text { آناليثر آمارى }
$$

نتايج به صورت ميانكين \pm انحراف استاندارد براى نمونهاي إنماي

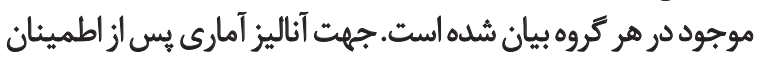

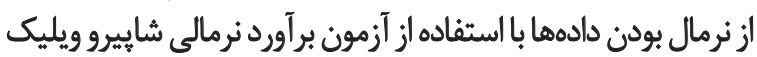
و براى بررسى فرض برابرى واريانسها از آزمون لون أون استفاده شادي.

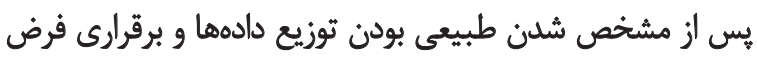

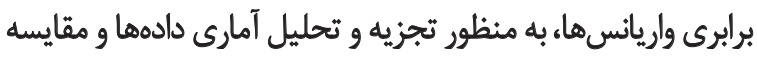

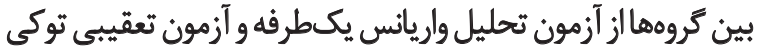

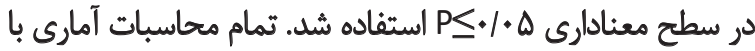

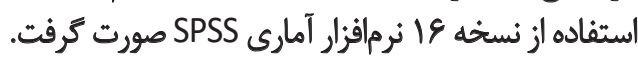

(Eastbiopharm مخصوص موش صحرايى (ساخت كشور جين إين

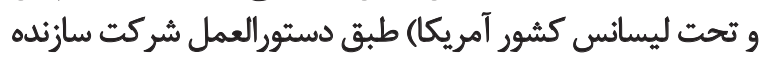

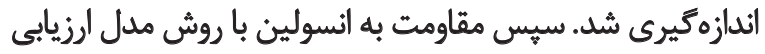

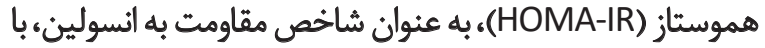
استفاده از فرمول شماره ا محاسبه شد:

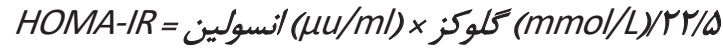

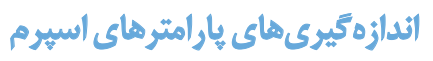

بلافاصله بعد از تشريح حيوان و وزن كردن بيضه جيّ آن،

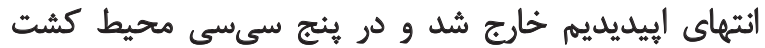
DMEM-F12)(Dulbecco's Modification of Eagle's) (Medium

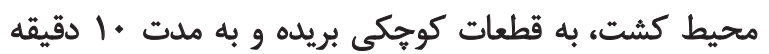

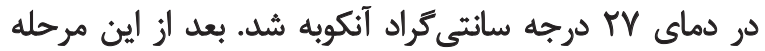

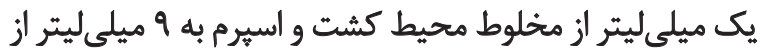

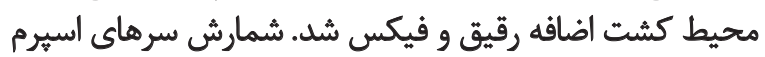

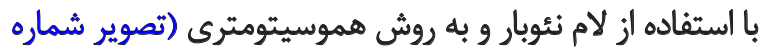

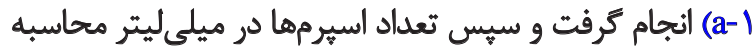

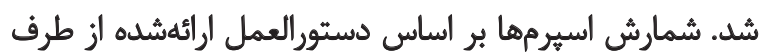
سازمان بهداشت جهانى' انجام شد [19].

قابليت تحرك اسيرم: سنجش حركات اسيرم بر اساس

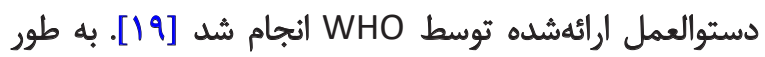

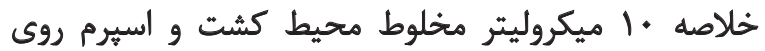

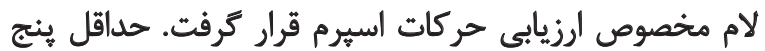

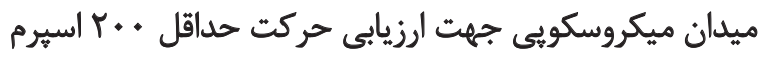

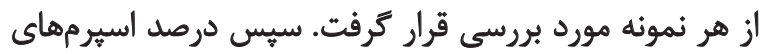

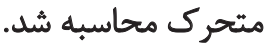

1. World Health Organization (WHO)

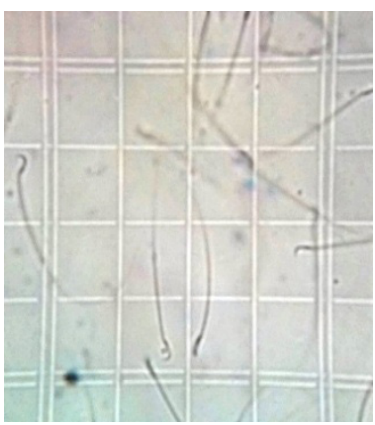

A

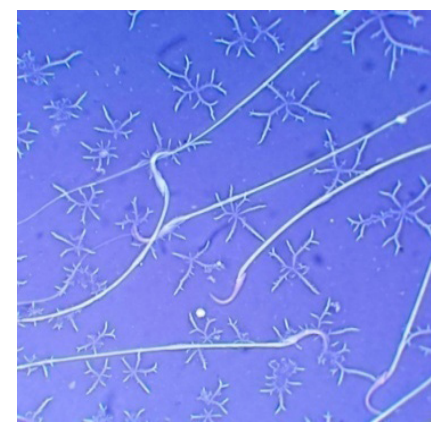

B

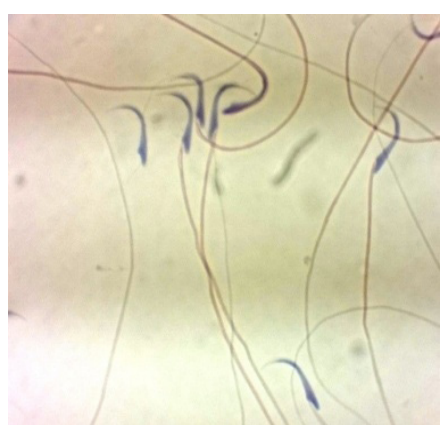

C

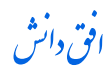

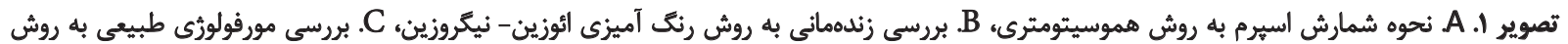

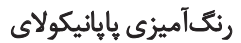


مشاهده نشد (P= (PAD). به علاوه بين گروه ديابتى تمرين

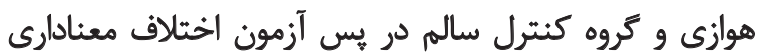

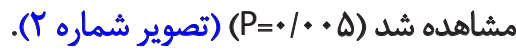

در بررسى سطح سرمى رزيستين در گروههاى مختلف، مشاهده

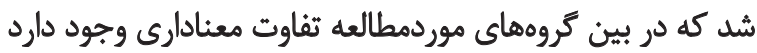

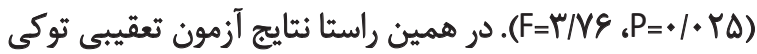

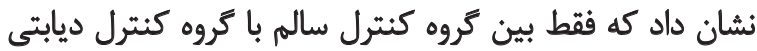

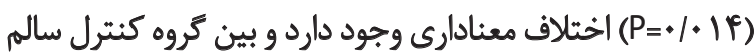

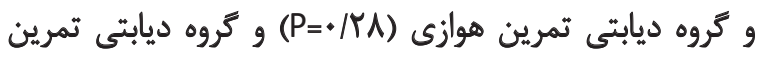

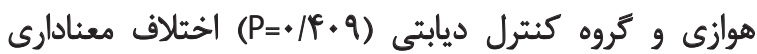
مشاهده نشد (تصوير شماره بَ). همجنين در بررسى سطح سرمى هورمون انسولين در سرما

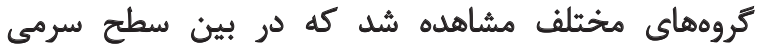

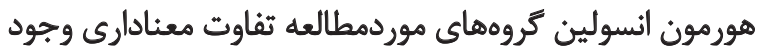

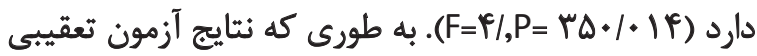

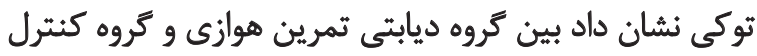

يافتهها

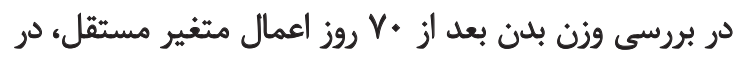

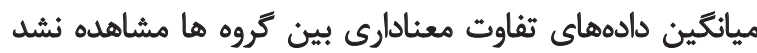

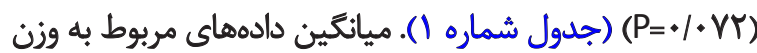

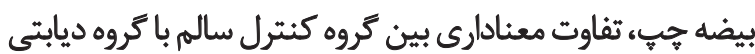

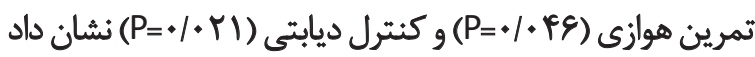

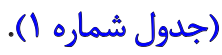

در بررسى ميزان قند خون كروهماي مختلف، قند خون ناشتيا

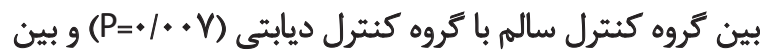

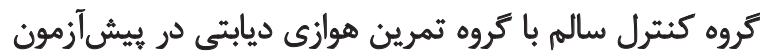

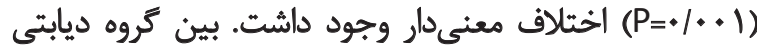

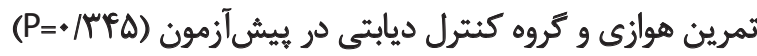

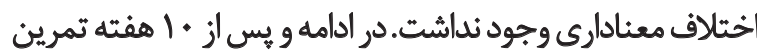

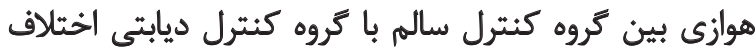

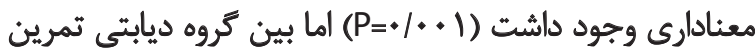

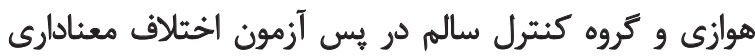

جدول ا. ميانكين وزن بلن و وزن بيضه جب دركروهاي مختلف

\begin{tabular}{|c|c|c|c|}
\hline وزن بيضه هِ (كرم) & \multicolumn{2}{|c|}{ وزن بدن (كرم) } & \multirow{3}{*}{ تمروه } \\
\hline \multicolumn{3}{|c|}{ ميانكيند|نحراف معيار } & \\
\hline يس آزمون & يس آزمون & ييش آزّمون & \\
\hline $1 / \varepsilon_{\Delta \pm}+/ 1 \phi$ & 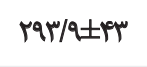 & $r r r / r \pm I r$ & كتترل سالم \\
\hline $1 / T \Delta \pm \cdot / r \Delta^{a}$ & $M T T / K \pm F \Delta$ & $r \mid \cdot / s \pm r g$ & كتترل ديابتى \\
\hline$V / T Y \pm \cdot / q^{b}$ & $r r \cdot|A \pm r|$ & $r \mid q / F \pm r$. & تمرين هوازى ديابتى \\
\hline
\end{tabular}

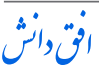

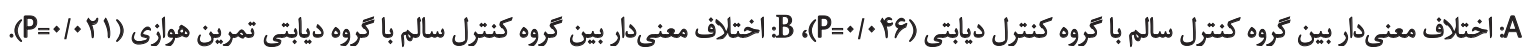

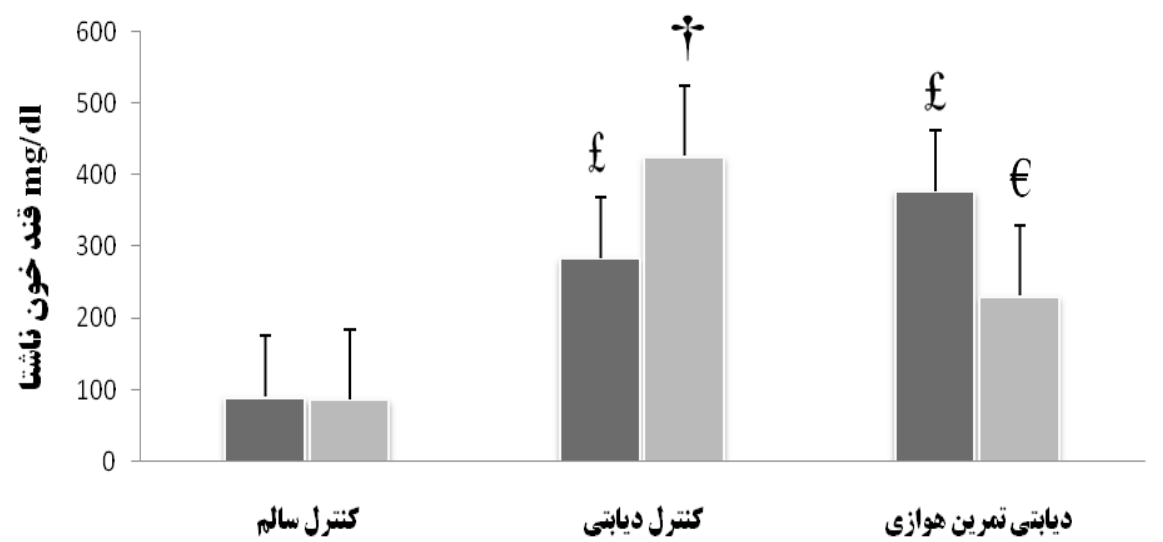

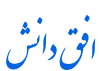

تصوير Y. قند خون ناشتا كروهماى تمرينى در هفته اول و انتهاى برنامه تمرين هوازى بعد از A هفته

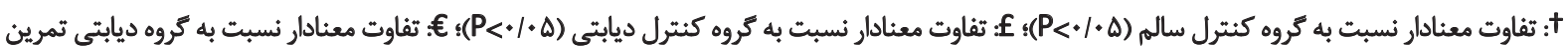

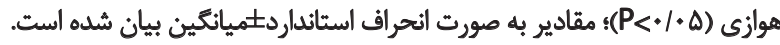




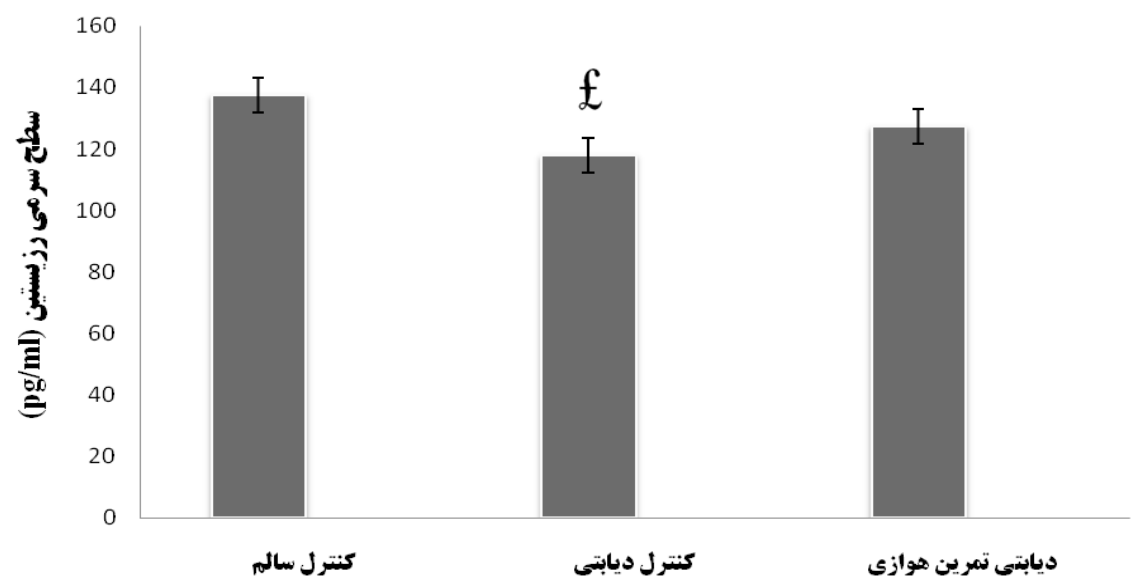

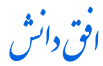

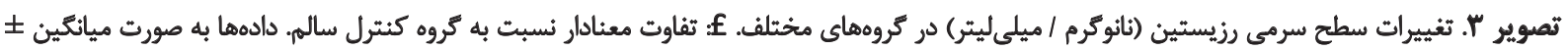

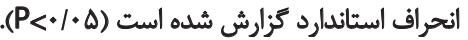

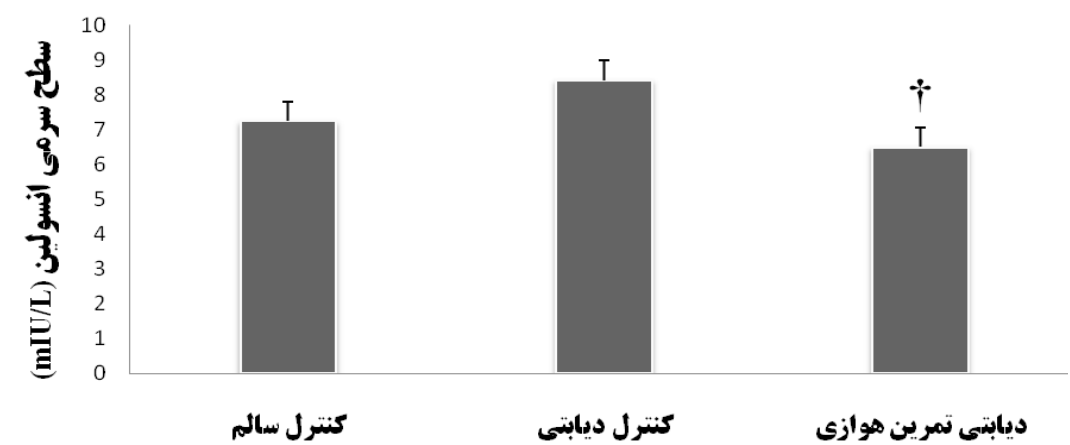

ن

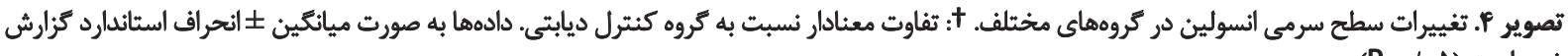

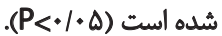

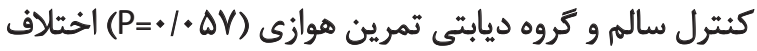
ديابتي (Pr) اختلاف معنادارى وجود دارد، اما بين كروه

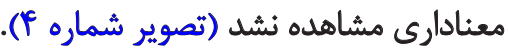

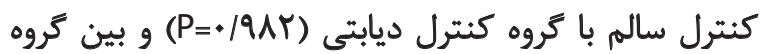

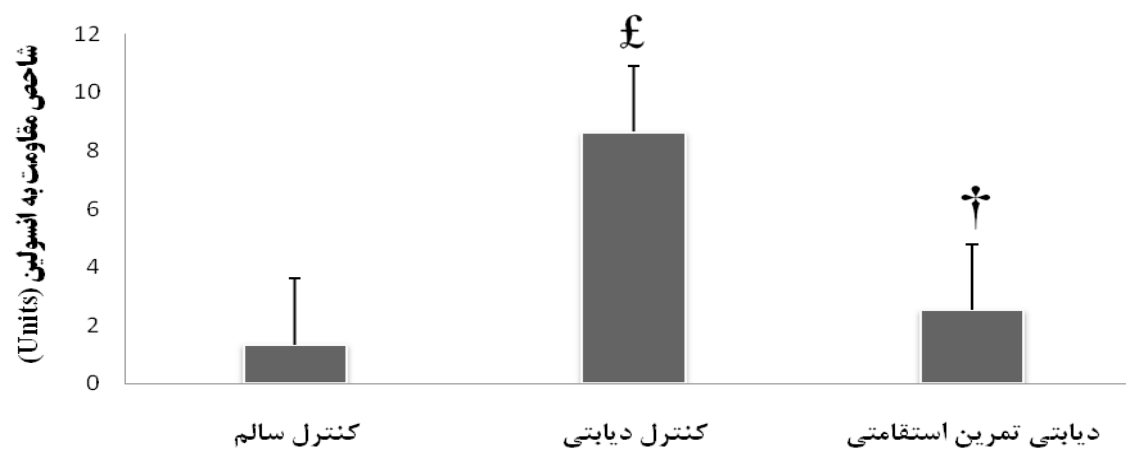

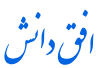

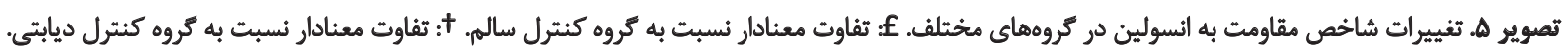

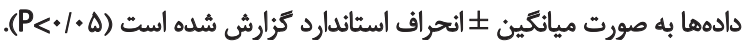


جدول r. مقايسه بارامترهاي اسيرم دركروهاي مختلف

\begin{tabular}{|c|c|c|c|c|}
\hline 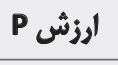 & كروه ديابتى تمرين هوازى & كروه كتترل ديابتى & كروه كتترل سالم & \multirow{2}{*}{ متغير } \\
\hline \multicolumn{4}{|c|}{ ميانكين 土|نحراف معيار } & \\
\hline$* *)^{*}$ & $r g / r \pm I r / r$ & $11 / V \Delta \pm \Delta / V$ & $r q / r \pm 1 r / \Delta$ & تعداد اسهير (1. (1. \\
\hline $.1 .01^{*}$ & $r \cdot / r \pm 9 / 0$ & $M / \Delta \pm V / /$ & $8 \cdot / A \pm 8 / 0$ & قابليت تحرى (درصد) \\
\hline $.1 . .1^{*}$ & FIN $\pm V / T$ & $r q / V A \pm 1 \& / r$ & W/atele & قابليت حيات (درصد) \\
\hline $.1 .1^{\circ}$ & WaDNA & $\Lambda \Delta / Y \Delta \pm V / \Delta$ & $9 \Delta / r \pm 1 / \%$ & مورفولوزى (درصد) \\
\hline
\end{tabular}

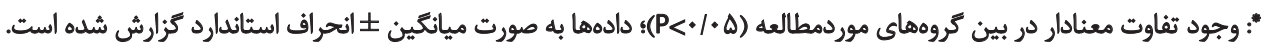

يافتهها حاكى از آن است كه ديابت مليتوس با القاى تغييرات

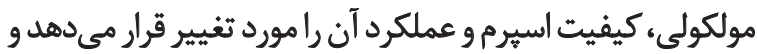

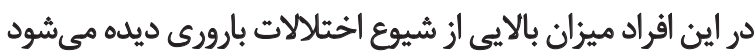

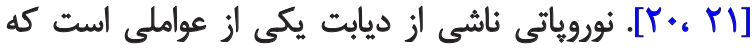

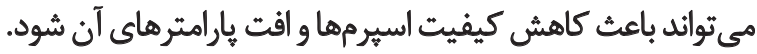

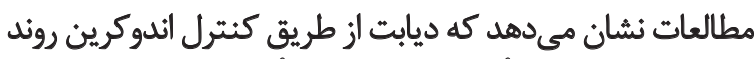

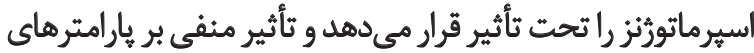

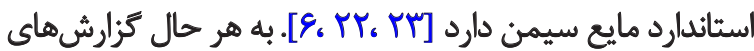

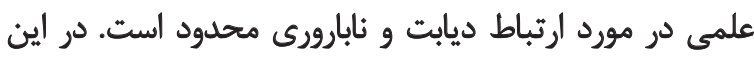

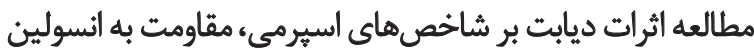

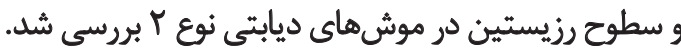

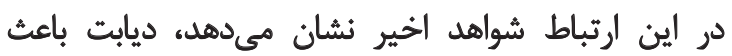

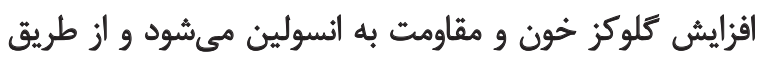

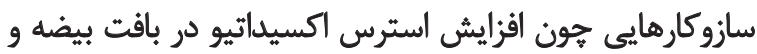

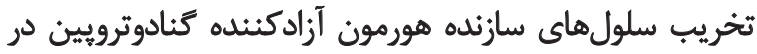

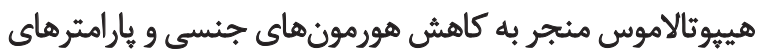

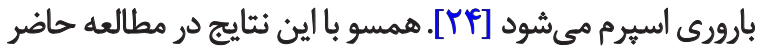

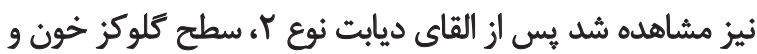

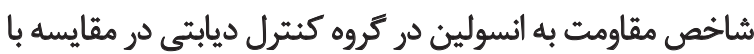

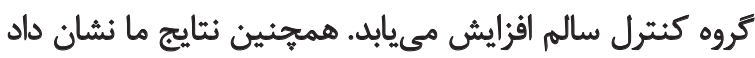

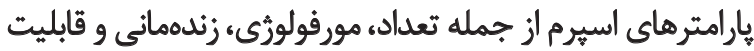

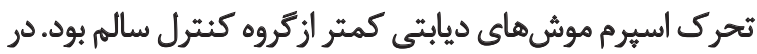

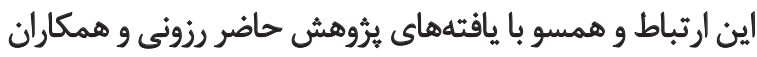

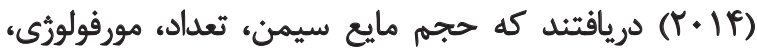

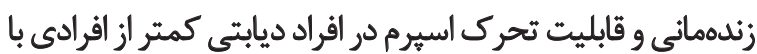

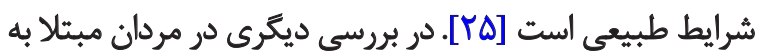

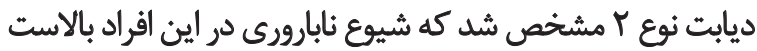

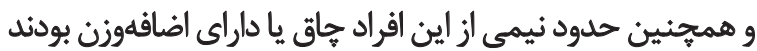

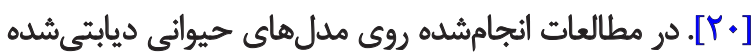

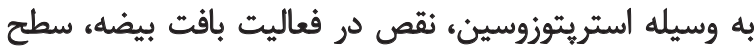

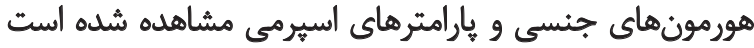

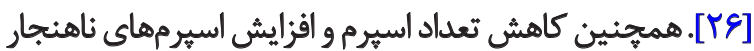

در بررسى شاخص مقاومت به انسولين (HOMA-IR) در

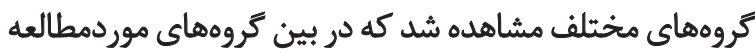

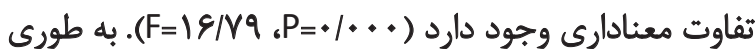

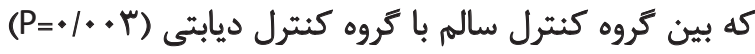

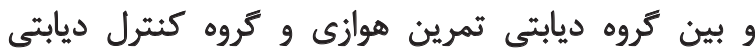

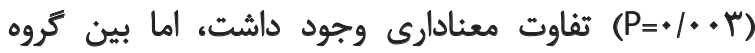
كنترل سالم و كروه ديابتى تمرين هوازى (P) (P)

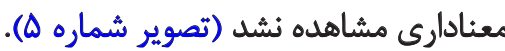

نتايج در مورد مقايسه تعداد اسيرم كروهها نشان داد اختلاف

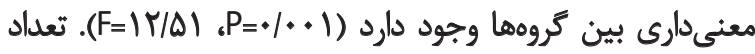

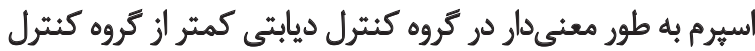

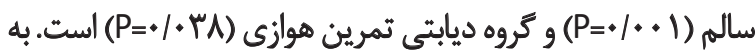

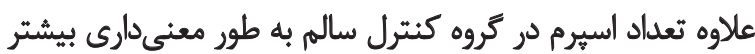

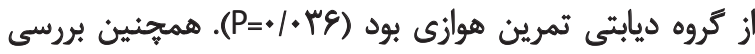

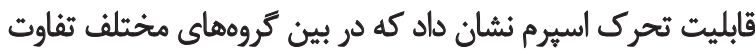

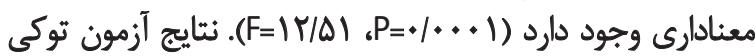

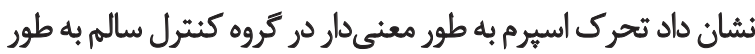

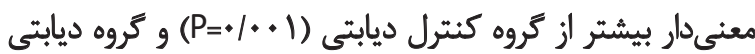

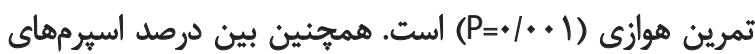

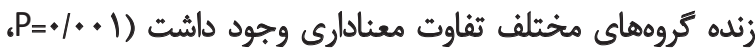

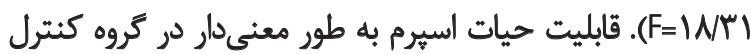

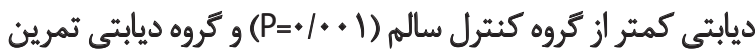

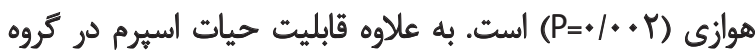

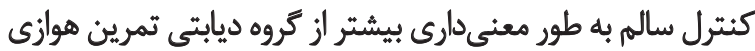

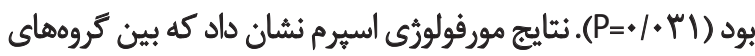

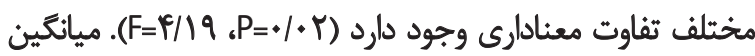

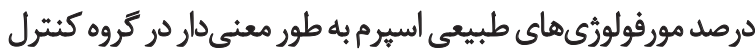

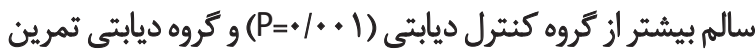

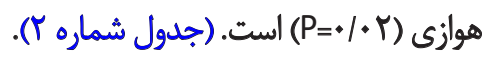
ث ديابت و ييامدهاى منفى آن در جهان رو به افزايش است. 


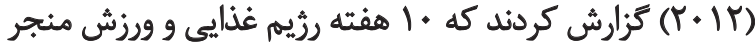

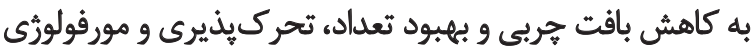

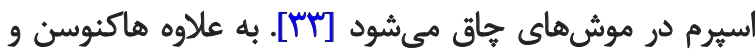

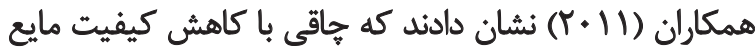

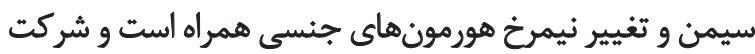

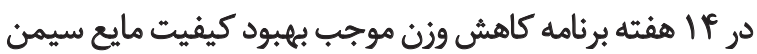

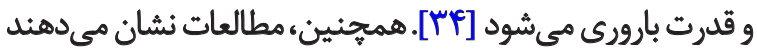

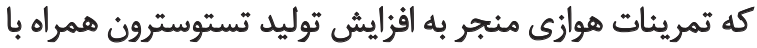

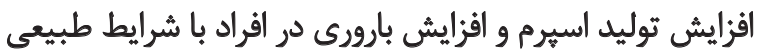

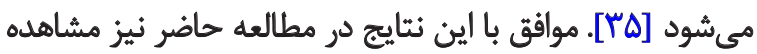

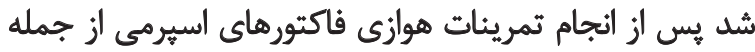

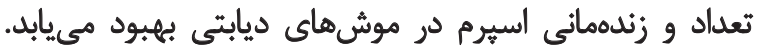

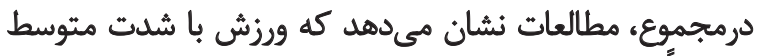

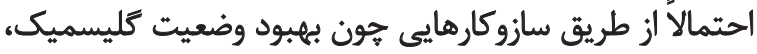

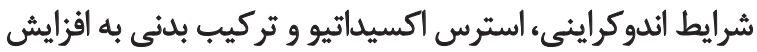

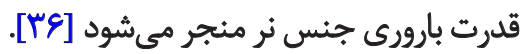

در يُوهش حاضر يس از انجام تمرين هوازى تفاوت معنى دارى

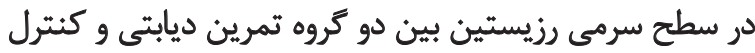

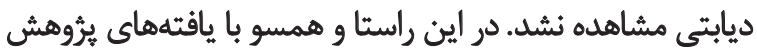

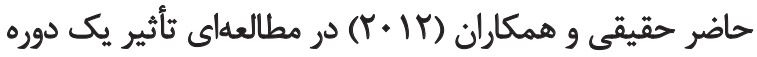

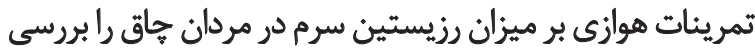

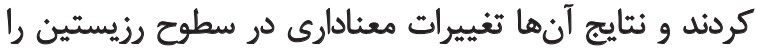

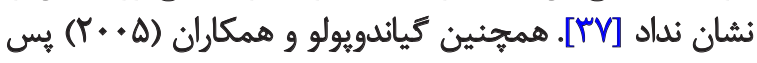

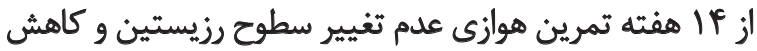

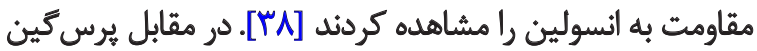

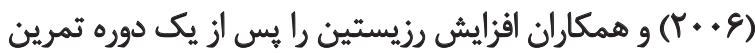

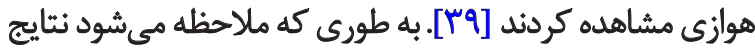

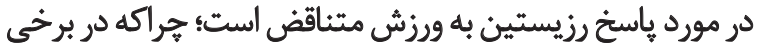

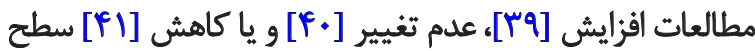

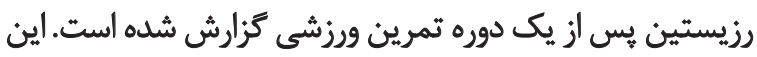

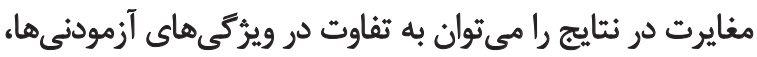

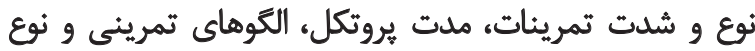

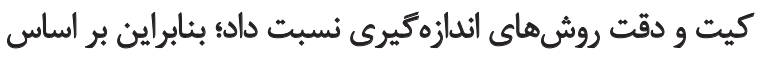

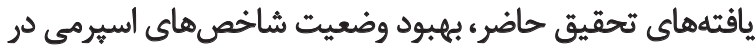

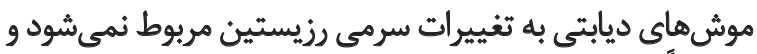

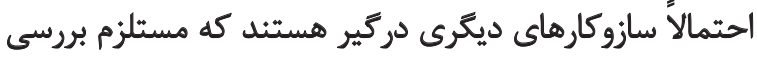

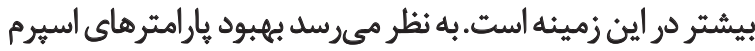

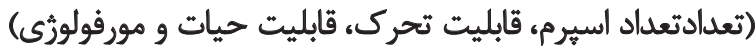

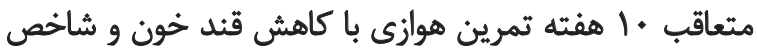

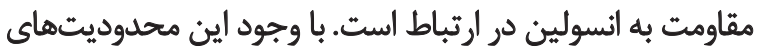

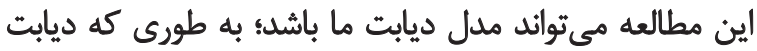

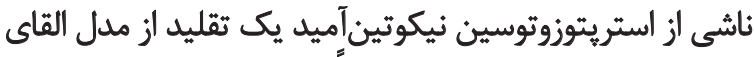

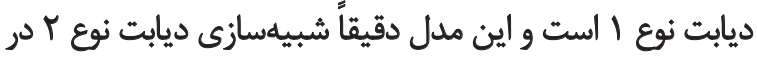

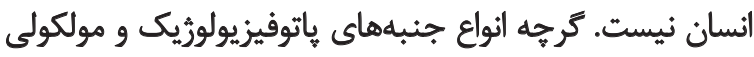

با شرايط ديابتى مرتبط است [ه].

در مطالعات تزارش شده است كه رزيستين و كيرندهاى

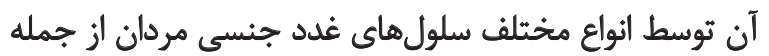

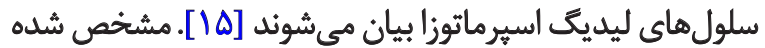

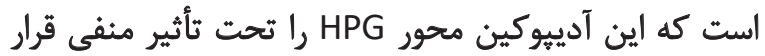

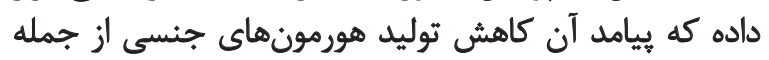

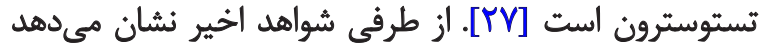

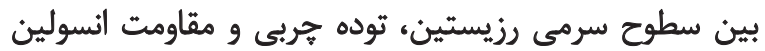

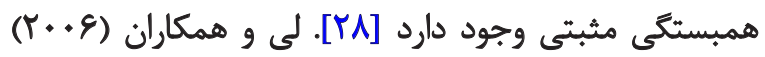

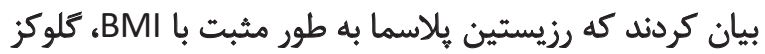

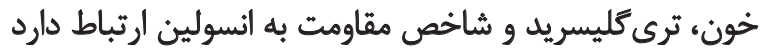

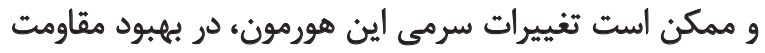

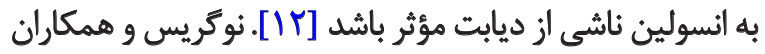

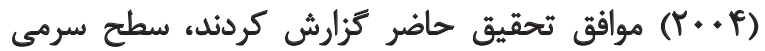

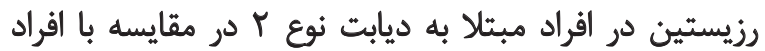

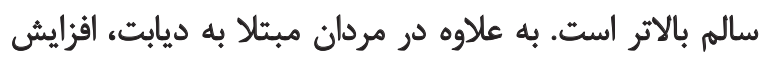

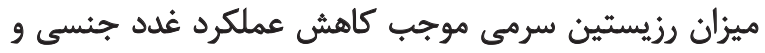

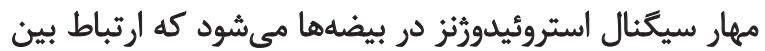

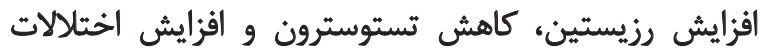

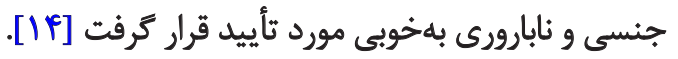

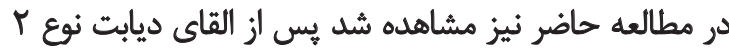

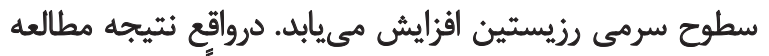

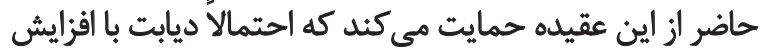

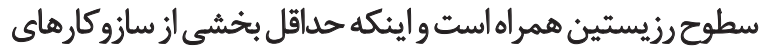

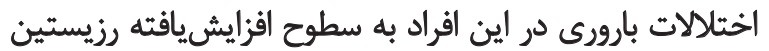

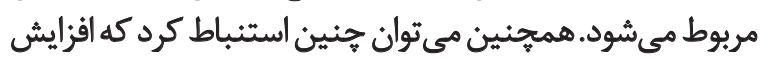

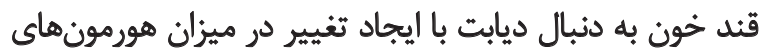

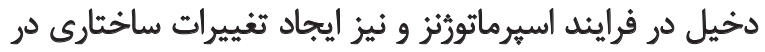

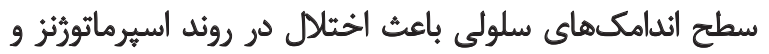

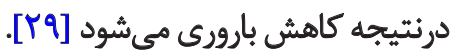

از سوى ديكر بيان شده است ورزش و فعاليت بدنى يكى راهكار

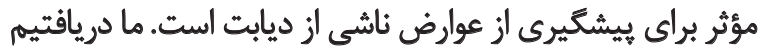

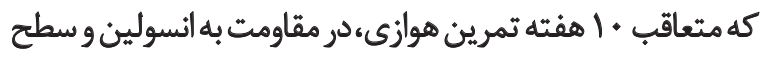

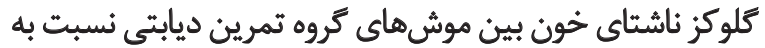

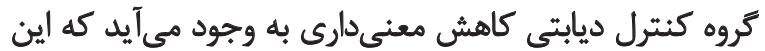

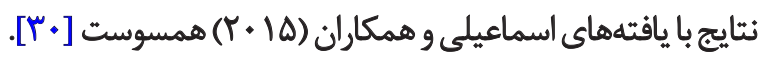

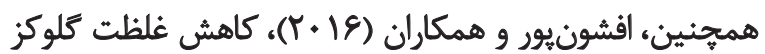

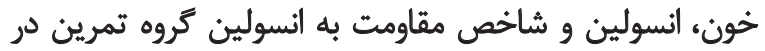

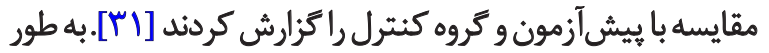

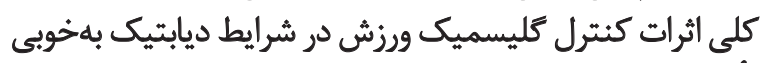

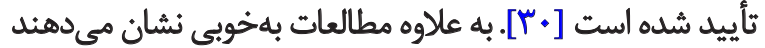

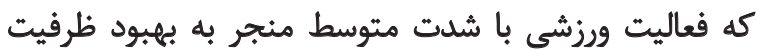

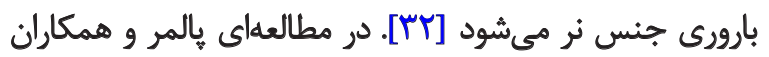


ديابت نوع | و ديابت نوع r شايع هستند، برخى از خصوصيات

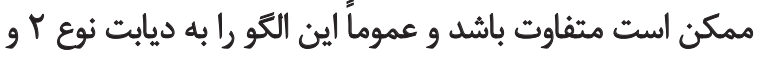
مقاومت به انسولين محدود مى كند.

$$
\text { نتيجهيرى }
$$

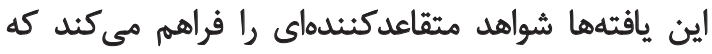
تمرين هوازى با شدت متوسط ممكن است مستقل ازئن از تغييرات

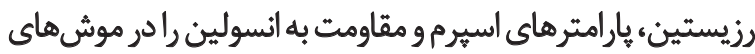
ديابتى شده با استريتوزوتوسين بهبود بخشد.

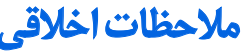

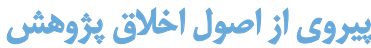

كد اخلاق اين يروهش (IR.Arakmu.rec.1394.329) از اخزيت

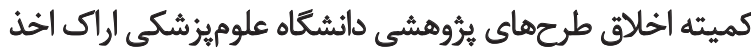

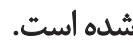

$$
\text { مامي مالى }
$$

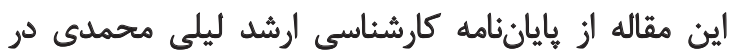

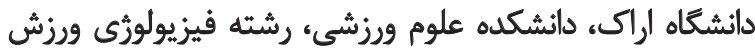
استخراج و بدون دريافت كمك مالى انجام شده استه فئه

$$
\text { مشاركت نويسندكّان }
$$

ايده اصلى: عباس صارمى و محمد يرستش؛ نكارش مقاله،

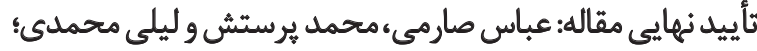
جمعآورى داده، تفسير دادهها: ليلى محمدى مارئ

$$
\text { تقارض مثأع }
$$

بدينوسيله نويسندكان تصريح مى كنيد كه هيجگونه تضاد منافعى در خصوص يثروهش حاضر وجود ندارد. 


\section{References}

[1] Pradhan AD, Manson JE, Rifai N, Buring JE, Ridker PM. C-reactive protein, interleukin 6, and risk of developing type 2 diabetes mellitus. JAMA. 2001; 286(3):327-34. [DOI:10.1001/jama.286.3.327] [PMID]

[2] Nasli-Esfahani E, Farzadfar F, Kouhnavard M, Ghodssi-Ghassemabadi R, Khajavi A, Peimani M, et al. Iran Diabetes Research Roadmap (IDRR) study: A preliminary study on diabetes research in the world and Iran. Journal of Diabetes and Metabolic Disorders. 2017; 16:9. [DOI:10.1186/ s40200-017-0291-9] [PMID] [PMCID]

[3] Hamilton BE, Ventura SJ. Fertility and abortion rates in the United States, 1960-2002. International Journal of Andrology. 2006; 29(1):3445. [DOI:10.1111/j.1365-2605.2005.00638.x] [PMID]

[4] Lutz W. Fertility rates and future population trends: Will Europe's birth rate recover or continue to decline? International Journal of Andrology. 2006; 29(1):25-33. [DOI:10.1111/j.1365-2605.2005.00639.x] [PMID]

[5] Ballester J, Muñoz MC, Domínguez J, Rigau T, Guinovart JJ, RodríguezGil JE. Insulin-dependent diabetes affects testicular function by FSHand LH-linked mechanisms. Journal of Andrology. 2004; 25(5):706-19. [DOI:10.1002/j.1939-4640.2004.tb02845.x] [PMID]

[6] Alves MG, Martins AD, Rato L, Moreira PI, Socorro S, Oliveira PF. Molecular mechanisms beyond glucose transport in diabetes-related male infertility. Biochimica et Biophysica Acta. 2013; 1832(5):626-35. [DOI:10.1016/j.bbadis.2013.01.011] [PMID]

[7] Vignon F, Le Faou A, Montagnon D, Pradignac A, Cranz C, Winiszewsky P, et al. Comparative study of semen in diabetic and healthy men. Diabète \& Métabolisme. 1991; 17(3):350-4. [PMID]

[8] Aitken RJ, Koppers AJ. Apoptosis and DNA damage in human spermatozoa. Asian Journal of Andrology. 2011; 13(1):36-42. [DOI:10.1038/ aja.2010.68] [PMID] [PMCID]

[9] Kondo T, Kobayashi I, Murakami M. Effect of exercise on circulating adipokine levels in obese young women. Endocrine Journal. 2006; 53(2): 189-95. [DOI:10.1507/endocrj.53.189] [PMID]

[10] Aruna B, Ghosh S, Singh AK, Mande SC, Srinivas V, Chauhan R, et al. Human recombinant resistin protein displays a tendency to aggregate by forming intermolecular disulfide linkages. Biochemistry. 2003; 42(36):10554-9. [DOI:10.1021/bi034782v] [PMID]

[11] Kusminski CM, McTernan PG, Kumar S. Role of resistin in obesity, insulin resistance and Type II diabetes. Clinical Science (London, England: 1979). 2005; 109(3):243-56. [DOI:10.1042/CS20050078] [PMID]

[12] Lu HL, Wang HW, Wen Y, Zhang MX, Lin HH. Roles of adipocyte derived hormone adiponectin and resistin in insulin resistance of type 2 diabetes. World Journal of Gastroenterology. 2006; 12(11):1747-51. [DOI:10.3748/wjg.v12.i11.1747] [PMID] [PMCID]

[13] Tsatsanis C, Dermitzaki E, Avgoustinaki P, Malliaraki N, Mytaras V Margioris AN. The impact of adipose tissue-derived factors on the Hypothalamic-Pituitary-Gonadal (HPG) axis. Hormones. 2015; 14(4):549-62. [DOI:10.14310/horm.2002.1649] [PMID]

[14] Nogueiras R, Barreiro ML, Caminos JE, Gaytán F, Suominen JS, Navarro VM, et al. Novel expression of resistin in rat testis: Functional role and regulation by nutritional status and hormonal factors. Journal of Cell Science. 2004; 117(Pt 15):3247-57. [DOI:10.1242/jcs.01196] [PMID]

[15] Normandin JJ, Murphy AZ. Somatic genital reflexes in rats with a nod to humans: Anatomy, physiology, and the role of the social neuropeptides. Hormones and Behavior. 2011; 59(5):656-65. [DOI:10.1016/j.yhh beh.2011.02.006] [PMID] [PMCID]
[16] No Authors Listed. Hip osteoarthritis can be treated with exercise. While no cure exists to date for this degenerative disease, exercise therapy can help alleviate symptoms and stave off surgery. DukeMedicine Healthnews. 2014; 20(12):3. [PMID]

[17] Kadoglou N, Perrea D, lliadis F, Angelopoulou N, Liapis C, Alevizos M. Exercise reduces resistin and inflammatory cytokines in patients with type 2 diabetes. Diabetes Care. 2007; 3(30):719-21. [DOI:10.2337/dc061149] [PMID]

[18] Afzalpour ME, Chadorneshin HT, Foadoddini M, Eivari HA. Comparing interval and continuous exercise training regimens on neurotrophic factors in rat brain. Physiology \& Behavior. 2015; 147:78-83. [DOI:10.1016/j. physbeh.2015.04.012] [PMID]

[19] Wang Y, Yang J, Jia Y, Xiong C, Meng T, Guan H, et al. Variability in the morphologic assessment of human sperm: Use of the strict criteria recommended by the World Health Organization in 2010. Fertility and Sterility. 2014; 101(4):945-9. [DOI:10.1016/j.fertnstert.2013.12.047] [PMID]

[20] La Vignera S, Condorelli R, Vicari E, D’Agata R, Calogero AE. Diabetes mellitus and sperm parameters. Journal of Andrology. 2012; 33(2):14553. [DOI:10.2164/jandrol.111.013193] [PMID]

[21] Corona G, Rastrelli G, Monami M, Saad F, Luconi M, Lucchese M, et al. Body weight loss reverses obesity associated hypogonadotropich hypogonadism: A systematic review and meta-analysis. European Journal of Endocrinology. 2013; 168(6):829-43. [DOI:10.1530/EJE-12-0955] [PMID]

[22] Singh AK, Tomarz S, Chaudhari AR, Sinqh R, Verma N. Type 2 diabetes mellitus affects male fertility potential. Indian Journal of Physiology and Pharmacology. 2014; 58(4):403-6. [PMID]

[23] Daubresse JC, Meunier JC, Wilmotte J, Luyckx AS, Lefebvre PJ. Pituitary-testicular axis in diabetic men with and without sexual impotence. Diabète \& Métabolisme. 1978; 4(4):233-7. [PMID]

[24] Rama Raju GA, Jaya Prakash G, Murali Krishna K, Madan K, Siva Narayana T, Ravi Krishna $\mathrm{CH}$. Noninsulin-dependent diabetes mellitus: Effects on sperm morphological and functional characteristics, nuclear DNA integrity and outcome of assisted reproductive technique. Andrologia. 2012; 44 Suppl 1:490-8. [DOI:10.1111/j.1439-0272.2011.01213.x] [PMID]

[25] Chandrashekar V, Bartke A. The impact of altered insulin-like growth factor-I secretion on the neuroendocrine and testicular functions. Minerva Ginecologica. 2005; 57(1):87-97

[26] Amaral S, Moreno AJ, Santos MS, Seiça R, Ramalho-Santos J. Effects of hyperglycemia on sperm and testicular cells of Goto-Kakizaki and streptozotocin-treated rat models for diabetes. Theriogenology. 2006; 66(9):2056-67. [DOI:10.1016/j.theriogenology.2006.06.006] [PMID]

[27] Morash BA, Willkinson D, Ur E, Wilkinson M. Resistin expression and regulation in mouse pituitary. FEBS Letters. 2002; 526(1-3):26-30 [DOI:10.1016/s0014-5793(02)03108-3] [PMID]

[28] Qatanani M, Szwergold NR, Greaves DR, Ahima RS, Lazar MA. Macrophage-derived human resistin exacerbates adipose tissue inflammation and insulin resistance in mice. The Journal of Clinical Investigation. 2009; 119(3):531-9. [DOI:10.1172/JCI37273] [PMID] [PMCID]

[29] Roessner C, Paasch U, Kratzsch J, Glander HJ, Grunewald S. Sperm apoptosis signaling in diabetic men. Reprod Biomed Online. 2012; 25(3) 292-299. [DOI:10.1016/j.rbmo.2012.06.004] [PMID]

[30] Esmaeili M, Bijeh N, Ghahremani Moghadam M. [Effect of combined aerobic and resistance training on aerobic fitness, strength, beta-endorphin, blood glucose level, and insulin resistance in women with type II 
diabetes mellitus (Persian)]. The Iranian Journal of Obstetrics, Gynecology and Infertility. 2018; 21(6):34-46. [DOI:10.22038/IJOGI.2018.11631]

[31] Afshon Pour MT, Habibi AH, Ranjbar RA. [Effects of continuous aerobic exercise training on plasma concentration of apelin and insulin resistance in type 2 diabetic men (Persian)]. Armaghane Danesh. 2016; 21(1):57-70. http://armaghanj.yums.ac.ir/article-1-1148-en.html

[32] Vaamonde D, Da Silva-Grigoletto ME, García-Manso JM, VaamondeLemos R, Swanson RJ, Oehninger SC. Response of semen parameters to three training modalities. Fertility and Sterility. 2009; 92(6):1941-6. [DOI:10.1016/j.fertnstert.2008.09.010] [PMID]

[33] Palmer NO, Bakos HW, Fullston T, Lane M. Impact of obesity on male fertility, sperm function and molecular composition. Spermatogenesis. 2012; 2(4):253-63. [DOI:10.4161/spmg.21362] [PMID] [PMCID]

[34] Håkonsen LB, Thulstrup AM, Aggerholm AS, Olsen J, Bonde JP, Andersen $\mathrm{CY}$, et al. Does weight loss improve semen quality and reproductive hormones? Results from a cohort of severely obese men. Reproductive Health. 2011; 8:24. [DOI:10.1186/1742-4755-8-24] [PMID] [PMCID]

[35] Parastesh M, Heidarianpour A, Sadegh M. Investigating the effects of endurance, resistance and combined training on reproductive hormones and sperm parameters of streptozotocin-nicotinamide diabetic male rats. Journal of Diabetes \& Metabolic Disorders. 2019; 18(2):273-9. [DOI:10.1007/s40200-018-0380-4] [PMID]

[36] du Plessis SS, Kashou A, Vaamonde D, Agarwal A. Is there a link between exercise and male factor infertility? The Open Reproductive Science Journal. 2011; 3:105-13. [DOI:10.2174/1874255601103010105]

[37] Haghighi AH, Yarahmadi H, lidarabadi A, Rafiepoor AR. [Effect of a period of aerobic training on serum resistin level in obese men (Persian)]. Medical Journal of Mashhad University of Medical Sciences. 2013; 56(1):31-8. [DOI:10.22038/MJMS.2013.456]

[38] Giannopoulou I, Fernhall B, Carhart R, Weinstock RS, Baynard T, Figueroa A, et al. Effects of diet and/or exercise on the adipocytokine and inflammatory cytokine levels of postmenopausal women with type 2 diabetes. Metabolism. 2005; 54(7):866-75. [DOI:10.1016/j.mee tabol.2005.01.033] [PMID]

[39] Perseghin G, Burska A, Lattuada G, Alberti G, Costantino F, Ragogna $F$, et al. Increased serum resistin in elite endurance athletes with high insulin sensitivity. Diabetologia. 2006; 49(8):1893-900. [DOI:10.1007/ s00125-006-0267-7] [PMID]

[40] Jones TE, Basilio JL, Brophy PM, McCammon MR, Hickner RC. Longterm exercise training in overweight adolescents improves plasma peptide YY and resistin. Obesity (Silver Spring, Md.). 2009; 17(6):1189-9. [DOI:10.1038/oby.2009.11] [PMID] [PMCID]

[41] Roberts CK, Izadpanah A, Angadi SS, Barnard RJ. Effects of an intensive short-term diet and exercise intervention: Comparison between normal-weight and obese children. American Journal of Physiology Regulatory, Integrative and Comparative Physiology. 2013; 305(5):R5527. [DOI:10.1152/ajpregu.00131.2013] [PMID] [PMCID] 
This Page Intentionally Left Blank 